\title{
Calcium titanate photocatalyst prepared by a flux method for reduction of carbon dioxide with water
}

\section{$\operatorname{AUTHOR(S):~}$}

Yoshida, Hisao; Zhang, Like; Sato, Masumi;

Morikawa, Takeshi; Kajino, Tsutomu; Sekito,

Takeshi; Matsumoto, Shinichi; Hirata, Hirohito

\section{CITATION:}

Yoshida, Hisao ...[et al]. Calcium titanate photocatalyst prepared by a flux method for reduction of carbon dioxide with water. Catalysis Today 2014, 251: 132-139

\section{ISSUE DATE:}

2014-11-27

URL:

http://hdl.handle.net/2433/198288

\section{RIGHT:}

(c) 2014 Elsevier. Licensed under the Creative Commons Attribution-NonCommercial-No Derivatives 4.0 International http://creativecommons.org/licenses/by-nc-nd/4.0/. NOTICE: this is the author's version of a work that was accepted for publication in Catalysis Today. Changes resulting from the publishing process, such as peer review, editing, corrections, structural formatting, and other quality control mechanisms may not be reflected in this document. Changes may have been made to this work since it was submitted for publication. A definitive version was subsequently published in Catalysis Today, Volume 251, 1 August 2015, Pages 132-139, doi:10.1016/j.cattod.2014.10.039; 許諾条件に より本文ファイルは2016-11-27に公開; この論文は出版社版でありません。引用の際には出版社版をご確認ご利用く ださい。; This is not the published version. Please cite only the published version. 


\section{Calcium titanate photocatalyst prepared by a flux method for reduction of}

\section{carbon dioxide with water}

\section{$\underline{\text { Hisao Yoshida, }},{ }^{\mathrm{a}, \mathrm{b} *}$ Like Zhang, ${ }^{\mathrm{c}}$ Masumi Sato, ${ }^{\mathrm{a}}$ Takeshi Morikawa, $^{\mathrm{d}}$ Tsutomu Kajino, $^{\mathrm{d}}$} Takeshi Sekito, ${ }^{\mathrm{e}}$ Shinichi Matsumoto, ${ }^{\mathrm{e}}$ Hirohito Hirata ${ }^{\mathrm{e}}$

${ }^{a}$ Kyoto University, Graduate School of Human and Environmental Studies, Kyoto 606-8501, Japan

${ }^{b}$ Kyoto University, Elements Strategy Initiative for Catalysts and Batteries (ESICB), Kyoto 615-8520, Japan

${ }^{c}$ Nagoya University, Graduate School of Engineering, Nagoya 464-8603, Japan

${ }^{d}$ Toyota Central R\&D Labs., Inc., Nagakute, Aichi 480-1192, Japan

e Toyota Motor Corporation, Toyota 471-8572, Japan

*Corresponding author:

Hisao Yoshida, Professor, Dr.

Course of Studies on Material Science

Department of Interdisciplinary Environment

Graduate School of Human and Environmental Studies

Kyoto University

Yoshida-nihonmatsu-cho, Sakyo-ku, Kyoto 606-8501, JAPAN

Phone: +81-75-753-6594

FAX: $\quad+81-75-753-2988$

E-mail: yoshida.hisao.2a@kyoto-u.ac.jp 


\begin{abstract}
Several calcium titanate samples were prepared by a flux method with various flux salts and various substrate concentration and also by a solid state reaction method. The prepared calcium titanate of various morphologies were loaded with Ag cocatalyst, and examined for the photocatalytic reduction of carbon dioxide with water. A sample prepared with a $\mathrm{NaCl}$ flux with a moderate concentration of solute exhibited the highest and stable photocatalytic activity for carbon monoxide production among the prepared samples. It is revealed that the large and flat facets could stabilize the Ag cocatalyst nanoparticles on the surface to enhance the photocatalytic activity for the carbon monoxide production.
\end{abstract}

Keywords: Heterogeneous photocatalyst, $\mathrm{CO}_{2}$ reduction, Artificial photosynthesis, Flux method. 


\section{Introduction}

Since we will probably continue to release much carbon dioxide into the atmosphere, we must establish a new technology for the reduction of carbon dioxide in consideration of the carbon cycle on the earth. In order to reduce carbon dioxide chemically, we need a suitable reductant and a suitable catalyst. Although methane or other organic compounds are known as reducing agents, the use of them would substantially involve the emission of carbon dioxide, which seems ineffective. Although hydrogen is a better reductant, at present hydrogen is usually produced from natural gas, which method also produces carbon dioxide eventually [1, 2]. The most effective reductant would be water that only releases oxygen after the reaction although the activation of water is usually not easy without consuming energy. Ii is known that photocatalysis can decompose water molecule to form hydrogen and oxygen at mild condition [3-6], which suggests that the photocatalyst can activate water to promote various reactions without consuming additional energy or reagents by using photoenergy, i.e., solar energy.

As one of the possible and attractive methods, heterogeneous photocatalytic reduction of carbon dioxide with water has been widely studied so far [7-16]. In the 1970s many kinds of photocatalytic systems employing $\mathrm{SrTiO}_{3}$ single crystal, $\mathrm{Zn}$-doped $\mathrm{GaP}$ photocathode and predominant semiconductor powders such as $\mathrm{TiO}_{2}, \mathrm{ZnO}, \mathrm{CdS}, \mathrm{GaP}$ and $\mathrm{SiC}$ were examined to reduce carbon dioxide with water and some kinds of products were detected [7-9]. In the most of these and subsequent studies, however, the formation of molecular oxygen was scarcely mentioned or much less than the expected quantity although oxygen must be formed as an oxidized product from water [10].

In 1993, Sayama and Arakawa found that $\mathrm{ZrO}_{2}$ photocatalysts produced hydrogen, oxygen and carbon monoxide from aqueous solution of $\mathrm{NaHCO}_{3}$ and a $\mathrm{Cu}$-loaded $\mathrm{ZrO}_{2}$ photocatalyst exhibited higher selectivity for the carbon monoxide [11]. In 2011, Kudo and co-workers reported that Ag-loaded $\mathrm{BaLa}_{4} \mathrm{Ti}_{4} \mathrm{O}_{15}$ photocatalysts produced these products from aqueous medium with a carbon dioxide flow system [12]. Recently, Ag-loaded $\mathrm{Ga}_{2} \mathrm{O}_{3}$ photocatalysts have been also studied [13-16]. In these photocatalytic systems, the following reactions would take place:

$$
\begin{aligned}
& \mathrm{CO}_{2}+2 \mathrm{H}^{+}+2 \mathrm{e}^{-} \rightarrow \mathrm{CO}+\mathrm{H}_{2} \mathrm{O} \\
& 2 \mathrm{H}^{+}+2 \mathrm{e}^{-} \rightarrow \mathrm{H}_{2} \\
& 2 \mathrm{H}_{2} \mathrm{O}+4 \mathrm{~h}^{+} \rightarrow \mathrm{O}_{2}+4 \mathrm{H}^{+}
\end{aligned}
$$


In these systems, two reactions, photocatalytic reduction of carbon dioxide to carbon monoxide (eq. 4) and photocatalytic water splitting (eq. 5), competitively proceeded, where the reaction selectivity would vary with the photocatalyst:

$$
\begin{aligned}
& \mathrm{CO}_{2} \rightarrow \mathrm{CO}+1 / 2 \mathrm{O}_{2} \\
& \mathrm{H}_{2} \mathrm{O} \rightarrow \mathrm{H}_{2}+1 / 2 \mathrm{O}_{2}
\end{aligned}
$$

Among the reported photocatalysts, the $\mathrm{Ag} / \mathrm{BaLa}_{4} \mathrm{Ti}_{4} \mathrm{O}_{15}$ photocatalyst consisted of plate-like particles with anisotropic structure [12], where the reduction to produce carbon monoxide occurred on the Ag cocatalyst located on the edges of the plates while the oxidation would progress on the $\mathrm{BaLa}_{4} \mathrm{Ti}_{4} \mathrm{O}_{15}$ surfaces, that is, it is considered that the reaction fields for reduction and oxidation would be separated to contribute to the high photocatalytic performance.

In the present study, in order to discuss the relationship between the morphologic structure of the photocatalyst and the photocatalytic activity for the reduction of carbon dioxide, we employed calcium titanate $\left(\mathrm{CaTiO}_{3}\right)$ as a semiconductor photocatalyst and a flux method (molten salt method) for the preparation of the photocatalyst. The $\mathrm{CaTiO}_{3}$ photocatalyst have both a conduction band with available potential for reduction of carbon dioxide and a valence bands with enough potential for oxidation of water to oxygen [17]. As for the activation of water, it has already been reported to be photocatalytically active for water splitting $[18,19]$ and photocatalytic steam reforming of methane $[19,20]$. In addition, the point of zero charge of the $\mathrm{CaTiO}_{3}$ in water is reported as $\mathrm{pH}_{\mathrm{PzC}}=3$ [21], i.e., the surface is negatively charged in neutral water, which may be advantageous for adsorption of carbon dioxide also in an aqueous solution. The flux method is expected to provide fine single crystals and thus this method has been applied to synthesize various micro or nano-sized photocatalysts in recent years, for example, many kinds of titanate photocatalysts were synthesized such as $\mathrm{Na}_{2} \mathrm{Ti}_{6} \mathrm{O}_{13}$ [22], $\mathrm{Na}_{2} \mathrm{Ti}_{3} \mathrm{O}_{7}$ [23], $\mathrm{K}_{2} \mathrm{Ti}_{6} \mathrm{O}_{13}$ [24,25], $\mathrm{SrTiO}_{3}$ [26], $\mathrm{La}_{2} \mathrm{Ti}_{2} \mathrm{O}_{7}[27,28], \mathrm{PbTiO}_{3}$ [29], $\mathrm{CaZrTi}_{2} \mathrm{O}_{7}$ [30] and $\mathrm{AgLi}_{1 / 3} \mathrm{Ti}_{2 / 3} \mathrm{O}_{2}$ [31], although $\mathrm{CaTiO}_{3}$ has not been reported yet. In the present study, we prepared several $\mathrm{CaTiO}_{3}$ samples by a flux method and a conventional solid state reaction method, and examined their photocatalytic performances for the carbon dioxide reduction with water.

\section{Experimental}


Most of the $\mathrm{CaTiO}_{3}$ samples were synthesized by a flux method from $\mathrm{CaCO}_{3}$ (Kojundo 99.99\%) and $\mathrm{TiO}_{2}$ (rutile, Kojundo 99.9\%) as solutes by using $\mathrm{CaCl}_{2}, \mathrm{KCl}$ or $\mathrm{NaCl}$ (Kishida 99.5\%) as a flux in the same manner as our previous work [25]. The molar ratio of $\mathrm{CaCO}_{3}$ to $\mathrm{TiO}_{2}$ was unity, and various concentrations of the solute $\left(x\right.$ mol\% as $\left.\mathrm{CaTiO}_{3}\right)$ in the molten salt mixture were examined, where $x$ was defined as: $x$ $[\mathrm{mol} \%]=\left(\right.$ amount of $\left.\mathrm{CaTiO}_{3}[\mathrm{~mol}]\right) /\left(\right.$ amount of $\mathrm{CaTiO}_{3}[\mathrm{~mol}]+$ amount of a flux $\left.[\mathrm{mol}]\right) \times 100$. The mixed starting materials were put into a platinum crucible, which was loosely covered by a lid, heated at a rate of $200 \mathrm{~K} \mathrm{~h}^{-1}$ to $1373 \mathrm{~K}$, held at this temperature for 10 hours, and then slowly cooled at a rate of $100 \mathrm{~K} \mathrm{~h}^{-1}$ to $773 \mathrm{~K}$, followed by being naturally cooled to room temperature in an electric furnace. It is considered that the decarbonation of $\mathrm{CaCO}_{3}$ would take place to form $\mathrm{CaO}$ species during heating, the mixture of the starting materials would be molten, and then both $\mathrm{CaO}$ and $\mathrm{TiO}_{2}$ clusters in the molten salt would react with each other to form $\mathrm{CaTiO}_{3}$ crystallites during the cooling step. The products were well washed with hot water (353 K) four times to remove the flux. These samples are referred to as $\mathrm{CTO}(f l u x, x)$, e.g., $\mathrm{CTO}(\mathrm{NaCl}, 5)$. Another sample was prepared by a solid state (SS) reaction method: the same starting materials, $\mathrm{CaCO}_{3}$ and $\mathrm{TiO}_{2}$, were dried at $383 \mathrm{~K}$, mechanically mixed in a stoichiometric ratio by a wet ball-milling method $\left(\mathrm{CaCO}_{3} 23 \mathrm{~g}, \mathrm{TiO}_{2} 18.6 \mathrm{~g}\right.$, alumina balls of $1 \mathrm{~g}$ and acetone of $80 \mathrm{ml}$ were used) for $24 \mathrm{~h}$, dried in an oven at $343 \mathrm{~K}$ overnight, and heated in air atmosphere at $1273 \mathrm{~K}$ or $1373 \mathrm{~K}$ for $10 \mathrm{~h}$ in an alumina crucible. These samples are referred to as CTO(SS, calcination temperature), e.g., CTO(SS, $1273 \mathrm{~K})$. Ag cocatalyst of 0.1 or $0.5 \mathrm{wt} \%$ ( $y$ wt\%) was loaded on the surface of the $\mathrm{CaTiO}_{3}$ photocatalysts by a photodeposition method, where methanol of $25 \mathrm{vol} \%$ was used as the reductant. The samples are referred to as $\mathrm{Ag}(y) / \mathrm{CTO}$, e.g., $\operatorname{Ag}(0.5) / \mathrm{CTO}(\mathrm{NaCl}, 40)$.

Powder X-ray diffraction (XRD) pattern was recorded at room temperature on a Rigaku diffractometer MiniFlexII/AP using Ni-filtered $\mathrm{Cu} \mathrm{K} \alpha$ radiation $(30 \mathrm{kV}, 15 \mathrm{~mA}$ ). We used the diffraction line at $2 \theta=33.1$ degree to estimate the mean crystallites size of the $\mathrm{CaTiO}_{3}$ samples with Scherrer equation, where a diffraction line of Si powder (Kishida) at 28.5 degree was used as a reference for the determination of the half maximum full-width. Diffuse reflectance (DR) UV-visible spectrum was recorded at room temperature on a JASCO V-570 equipped with an integrating sphere covered with $\mathrm{BaSO}_{4}$, where $\mathrm{BaSO}_{4}$ was used as the reference. The bandgap was estimated from the spectra according to Tauc plot [32]. The Brunauer-EmmettTeller (BET) specific surface area was calculated from the amount of $\mathrm{N}_{2}$ adsorption at $77 \mathrm{~K}$, which was 
measured by a Quantachrome Monosorb. Field emission scanning electron microscopy (FE-SEM) images were recorded by a JEOL JSM-7500FA or a Hitachi S-5200. The sizes of particles were measured for around fifty particles by a scale on the SEM images, and the average particle size was determined for each sample.

Photocatalytic reactions were carried out in a specially designed reactor of gas-liquid-solid three phases (Fig. 1) under a flow of $\mathrm{CO}_{2}$ (Taiyo Nippon Sanso, 99.999\%) gas upon photoirradiation from the bottom $\left(16 \mathrm{~cm}^{2}\right)$ by a $300 \mathrm{~W}$ xenon lamp without passing any optical filters, which entirely emitted from UV to visible light, under ambient temperature and pressure. In a quartz cell, $0.2 \mathrm{~g}$ of the photocatalyst powder was dispersed in $10 \mathrm{~mL}$ of water saturated with $11 \mathrm{mmol}$ of $\mathrm{NaHCO}_{3}$ (Wako, >99.5\%). The $\mathrm{pH}$ of the solution was 8.3. The mixture of the solution and the photocatalyst powder was photoirradiated with magnetically stirring, where the reaction occurred. The incident light intensity measured in the range of 254 $\pm 10 \mathrm{~nm}$ at the center of the cell was $22 \mathrm{~mW} \mathrm{~cm}{ }^{-2}$, and the temperature of the reaction cell became $323 \mathrm{~K}$ during the photoirradiation. At regular interval (typically every $1 \mathrm{~h}$ ), the outlet gas was collected in a sampling column and introduced to an online gas chromatograph with a thermal conductivity detector to determine the amount of $\mathrm{H}_{2}, \mathrm{O}_{2}$ and $\mathrm{CO}$. The production rate of $\mathrm{H}_{2}$ and $\mathrm{CO}$ was precisely determined in this method. The amount of $\mathrm{O}_{2}$ was determined by the subtraction of the amount of air leak into the system, which sometimes contained large error unfortunately. Other products were not observed in this method. Selectivity for CO in the reduced products, $\mathrm{S}_{\mathrm{CO}}$ was defined as follows: $\mathrm{S}_{\mathrm{CO}}(\%)=100 \times$ (production rate of CO) / (Sum of production rates of $\mathrm{CO}$ and $\mathrm{H}_{2}$ ). The ratio of the electrons and holes consumed, $\mathrm{e}^{-} / \mathrm{h}^{+}$was calculated from the production rate as follows: $\mathrm{e}^{-} / \mathrm{h}^{+}=$(Sum of production rates of $\mathrm{CO}$ and $\mathrm{H}_{2}$ ) / (production rate of $\left.\mathrm{O}_{2} \times 2\right)$.

\section{Results and discussion}

\subsection{Characterization}

Fig. 2 shows $\mathrm{XRD}$ patterns of representative $\mathrm{CaTiO}_{3}$ samples and a calculated one from a database (ICSD \#74212). All the CTO samples exhibited clear diffraction lines assignable to $\mathrm{CaTiO}_{3}$ crystal and no other diffraction lines from impurity was observed in these profiles, indicating that these prepared CTO samples predominantly consisted of the $\mathrm{CaTiO}_{3}$ crystallites. It is noted that any kind of flux such as $\mathrm{CaCl}_{2}$, $\mathrm{KCl}$ and $\mathrm{NaCl}$ provided $\mathrm{CaTiO}_{3}$ crystallites. Even when excess amount of molten $\mathrm{CaCl}_{2}$ was used as a flux, 
no other calcium-rich compounds such as $\mathrm{Ca}_{3} \mathrm{Ti}_{2} \mathrm{O}_{7}$ and $\mathrm{Ca}_{4} \mathrm{Ti}_{3} \mathrm{O}_{10}$ [33] were formed. This result revealed that the composition of calcium titanate would be determined by not the solute concentration $(x$ mol\%) in the molten salt mixture and the kind of the flux but the atomic ratio of the starting materials, i.e., $\mathrm{CaCO}_{3}$ and $\mathrm{TiO}_{2}$. In the present case, the atomic ratio of $\mathrm{Ca}$ and $\mathrm{Ti}$ was unity, which thus provided $\mathrm{CaTiO}_{3}$ crystallites. In other words, the $\mathrm{CaTiO}_{3}$ crystallites would originate from $\mathrm{TiO}_{2}$ and $\mathrm{CaCO}_{3}$. It is considered that $\mathrm{CaO}$ clusters dissolved in the molten salt, which could be formed from $\mathrm{CaCO}_{3}$ by thermal decomposition, would predominantly react with dissolved $\mathrm{TiO}_{2}$ clusters to form the $\mathrm{CaTiO}_{3}$ crystallites, while $\mathrm{Ca}^{2+}$ cation of the $\mathrm{CaCl}_{2}$ flux could not be react with $\mathrm{TiO}_{2}$ species in the present condition, as previously discussed [25]. It is also noted that, even the crystallization of $\mathrm{CaTiO}_{3}$ took place in other molten salts, such as $\mathrm{KCl}$ and $\mathrm{NaCl}$, no compounds containing $\mathrm{K}$ and Na would be formed. Thus, it is clear that these alkali chloride fluxes such as $\mathrm{CaCl}_{2}, \mathrm{KCl}$ and $\mathrm{NaCl}$ could not react with $\mathrm{TiO}_{2}$ and could not exchange with the Ca cation in the crystallites of $\mathrm{CaTiO}_{3}$ in this condition. The average crystallites size of the samples were estimated from XRD profiles (Table 1), which clarified that the $\mathrm{CTO}\left(\mathrm{CaCl}_{2}, 5\right)$ sample obviously had larger crystallites than others.

The FE-SEM images revealed that the use of $\mathrm{CaCl}_{2}, \mathrm{KCl}$ and $\mathrm{NaCl}$ as a flux gave various morphologies. In some cases, various facets could be found on their surfaces. The $\mathrm{CaCl}_{2}$ flux gave clear and large cubic-like crystals of 2-30 $\mu \mathrm{m}$ on a side (Fig. 3a), which consisted of relatively larger crystals than others. By using the $\mathrm{KCl}$ flux, a mixture of small roundish particles of $0.1-0.5 \mu \mathrm{m}$ in diameter and long rodlike crystals of 3-8 $\mu \mathrm{m}$ in length was obtained in this condition (Fig. 3b). The $\mathrm{NaCl}$ flux provided polyhedral particles of 1-7 $\mu \mathrm{m}$ in diameter (Fig. 3c), where some facets were found on the surfaces. The CTO(SS,1273) sample showed tightly connected roundish and polyhedral particles (Fig. 3d). The size of the particles observed in these SEM images was in the range of $0.1-30 \mu \mathrm{m}$. On the other hand, the average crystallites sizes of these samples determined from XRD were ranged between 25-100 nm (Table 1). This discrepancy indicates that these particles of unique morphology observed in the SEM images would not be single crystals but polycrystals.

Although the color of the prepared CTO sample slightly varied with the preparation condition, most of them seemed pale purple or pale pink. Fig. 4 shows DR UV-visible spectra of the representative CTO samples. The adsorption edge is observed around $350 \mathrm{~nm}$ in wavelength for each samples. The estimated 
bandgap of these samples was around $3.6 \mathrm{eV}$ (Table 1). Among these samples, it can be said that the sample consisting of larger crystallites tended to exhibit smaller bandgap. The CTO(SS,1273) sample exhibited also a shoulder band around 350-400 nm in wavelength (Fig. 4e), which might originate from electron transition from the valence band to shallow trap sites below the conduction band due to oxygen vacancies, or from unreacted $\mathrm{TiO}_{2}$. Since no $\mathrm{TiO}_{2}$ phase was detected in the XRD profiles, it should be amorphous $\mathrm{TiO}_{2}$ species if existed. Anyway, judging from the color of the sample, there would be some kinds of defects on the CTO(SS,1273) sample. The $\mathrm{CTO}\left(\mathrm{CaCl}_{2}, 5\right)$ sample exhibited also a similar band in the range of 350-420 nm in wavelength as well as a broad absorption band in the visible light region of 420-800 nm (Fig. 4a). The latter would originate from some kinds of lattice defects or surface defects like as color centers. This means that the $\mathrm{CTO}\left(\mathrm{CaCl}_{2}, 5\right)$ sample had some kinds of defects although it consisted of the large cubic-like crystals shown in the SEM image (Fig. 3a). In the Table 1, BET specific surface area of the samples were listed, and the $\mathrm{CTO}\left(\mathrm{CaCl}_{2}, 5\right)$ sample exhibited a large value. These facts suggest that the large cubic-like crystals might be microporous although it could not be recognized on the SEM image. The $\mathrm{CTO}(\mathrm{NaCl}, 5)$ and $\mathrm{CTO}(\mathrm{NaCl}, 40)$ samples showed only a very week and broad absorption band in this visible light region (Fig. 4c and 4d), implying that these samples had less defects than the $\mathrm{CTO}\left(\mathrm{CaCl}_{2}, 5\right)$ and $\mathrm{CTO}(\mathrm{SS}, 1273)$ samples. The $\mathrm{CTO}(\mathrm{KCl}, 5)$ sample showed no absorption in the range of longer than $350 \mathrm{~nm}$ in wavelength (Fig. 4b), suggesting that this sample had the lowest amount of such kind of defects among these samples.

\subsection{Photocatalytic performance}

Photocatalytic tests for $\mathrm{CO}_{2}$ reduction with $\mathrm{H}_{2} \mathrm{O}$ as a reductant without using any sacrificial reagents were carried out in a flow reactor, where the formation rates for each product were determined. Fig. 5 shows the time course of the production rates on the $\mathrm{Ag}(0.5) / \mathrm{CTO}(\mathrm{NaCl}, 40)$ sample. The products were $\mathrm{CO}, \mathrm{H}_{2}$, and $\mathrm{O}_{2}$, where $\mathrm{CO}$ was the reduction product from $\mathrm{CO}_{2}$ and $\mathrm{H}_{2}$ was produced by water splitting as a competitive reaction [11-14]. The production rates of $\mathrm{CO}$ and $\mathrm{H}_{2}$ were initially high but decreased steeply in the initial period for 5 hours. After this unstable period, the production rate of $\mathrm{CO}$ and $\mathrm{H}_{2}$ became constant. On the other hand, evolution of $\mathrm{O}_{2}$ was not observed at the initial stage, where oxygen might be adsorbed on the surface of photocatalyst [34-38] or consumption for oxidizing the photocatalyst or Ag cocatalyst. After the initial period, the production rate of $\mathrm{O}_{2}$ also became constant. In the present reaction system, it is 
suggested that the above mentioned reactions shown in the equations (1)-(3) would take place. Without Ag cocatalyst, or without the photoirradiation, the reaction did not proceed. The reaction continuously lasted in the constant rate even after 24 hours. Thus, it is proposed that the reaction would photocatalytically proceed in the constant rate, at least at the steady state after the initial period.

The Ag cocatalyst would receive the photoexcited electrons from the conduction band of the $\mathrm{CaTiO}_{3}$ semiconductor and function as the reduction sites for production of $\mathrm{CO}$ and $\mathrm{H}_{2}$ shown in equations (1) and (2), respectively. Since other cocatalysts such as Pt, Rh, and Pd did not promote the production of CO and $\mathrm{Cu}$ cocatalyst promoted $\mathrm{CO}$ formation at very low rate $\left(0.016 \mu \mathrm{mol} \mathrm{h} \mathrm{h}^{-1}\right)$, the $\mathrm{Ag}$ cocatalyst is especially important for $\mathrm{CO}_{2}$ reduction to produce $\mathrm{CO}$ on the present photocatalyst. This would be related to the less adsorption ability of Ag metal for CO molecule.

Table 2 shows the production rates after 5 and 20 hours from the start of the photocatalytic reaction. It is obvious that the photocatalytic reduction of $\mathrm{CO}_{2}$ proceeded over all the Ag-loaded $\mathrm{CaTiO}_{3}$ samples. The selectivity to $\mathrm{CO}$, i.e., the reaction selectivity for $\mathrm{CO}_{2}$ reduction, was also listed in Table 2, which much varied with the sample. The consumed ratio of the electrons and holes $\left(\mathrm{e}^{-} / \mathrm{h}^{+}\right)$was also listed in Table 2, which should be unity since photocatalysis must consume equivalent amounts of photoexcited electrons and holes, and most of the samples actually showed the $\mathrm{e}^{-} / \mathrm{h}^{+}$ratio close to unity at the steady state (20 h later). As for the samples of low activity, the oxygen evolution rate was often not determined correctly.

The three samples prepared by the different flux with the same solute concentration, the $\mathrm{Ag}(0.1) / \mathrm{CTO}\left(\mathrm{CaCl}_{2}, 5\right), \quad \mathrm{Ag}(0.1) / \mathrm{CTO}(\mathrm{KCl}, 5)$ and $\mathrm{Ag}(0.1) / \mathrm{CTO}(\mathrm{NaCl}, 5)$ samples, exhibited stable production rates at $20 \mathrm{~h}$ later, and the $\mathrm{e}^{-} / \mathrm{h}^{+}$values became closed to unity (Table 2 , entries $1-3$ ), suggesting that the photocatalytic reaction clearly proceeded on each sample. However, the selectivity was different from each other. The $\mathrm{Ag}(0.1) / \mathrm{CTO}\left(\mathrm{CaCl}_{2}, 5\right)$ sample of unique cubic-like morphology exhibited high and selective photocatalytic activity for not $\mathrm{CO}_{2}$ reduction but water splitting to produce $\mathrm{H}_{2}$ and $\mathrm{O}_{2}$. This sample had larger size of crystallites and larger surface area (Table 1, entry 1), which might contribute to the high and selective photocatalytic activity for water splitting although this sample showed some absorption band probably due to defects (Fig. 4a). On the other hand, the $\mathrm{Ag}(0.1) / \mathrm{CTO}(\mathrm{NaCl}, 5)$ sample showed the highest CO selectivity among the three samples (Table 1 , entry 3$)$. This $\mathrm{Ag}(0.1) / \mathrm{CTO}(\mathrm{NaCl}, 5)$ sample prepared by 
the flux method was higher than the $\mathrm{Ag}(0.1) / \mathrm{CTO}(\mathrm{SS}, 1273)$ and $\mathrm{Ag}(0.1) / \mathrm{CTO}(\mathrm{SS}, 1373)$ sample prepared by the solid state reaction method (Table 1, entries 10 and 11).

Thus, the effect of the solute concentration was examined on the $\mathrm{Ag}(y) / \mathrm{CTO}(\mathrm{NaCl}, x)$ samples, which results were listed in Table 2, entries 3-5 for the $\mathrm{Ag}(0.1) / \mathrm{CTO}(\mathrm{NaCl}, x)$ samples and entries $6-10$ for the $\mathrm{Ag}(0.5) / \mathrm{CTO}(\mathrm{NaCl}, x)$ samples. The CO production rate and $\mathrm{CO}$ selectivity were plotted in Fig. 6A. Both the $\mathrm{CO}$ production rates and the $\mathrm{CO}$ selectivity on both the $\mathrm{Ag}(0.1) / \mathrm{CTO}(\mathrm{NaCl}, x)$ samples and the $\mathrm{Ag}(0.5) / \mathrm{CTO}(\mathrm{NaCl}, x)$ samples presented each volcano plot upon the solute concentration, where the $\mathrm{Ag}(0.1) / \mathrm{CTO}(\mathrm{NaCl}, 50)$ sample and the $\mathrm{Ag}(0.5) / \mathrm{CTO}(\mathrm{NaCl}, 40)$ sample corresponded to the peaks of the volcano plots for the $\mathrm{Ag}(0.1) / \mathrm{CTO}(\mathrm{NaCl}, x)$ samples and the $\mathrm{Ag}(0.5) / \mathrm{CTO}(\mathrm{NaCl}, x)$ samples, respectively. The most active one in the present study was the $\operatorname{Ag}(0.5) / \mathrm{CTO}(\mathrm{NaCl}, 40)$ sample, which exhibited the $\mathrm{CO}$ production rate of $0.35 \mathrm{\mu mol} \mathrm{h}^{-1}$ and the selectivity for the $\mathrm{CO}_{2}$ reduction was as high as $45 \%$ (Table 2 entry 7). It is noted that the CO production rates over these samples prepared by the flux method (Table 2, entries 4 and 7) were 10 times higher than that over the samples prepared by the solid state reaction method (Table 2, entries 11 and 12). The CO selectivity was also obviously higher for these samples prepared by the flux method than those by the solid state reaction method.

Fig. 7 shows some representative FE-SEM images of these CTO samples before loading Ag cocatalyst. All the samples consisted of the polyhedral particles covered with many facets. The particle size observed in the images varied with the solute concentration and it is clear that the $\mathrm{CTO}(\mathrm{NaCl}, 40)$ sample had the larger polyhedral polycrystals than others. The average particle sizes of the polycrystals estimated from the SEM images for the $\mathrm{CTO}(\mathrm{NaCl}, x)$ samples were plotted upon the solute concentration in Fig. 6B. It is interesting that the similar volcano plot appered as Fig. 6A. Thus, the CO production rates were plotted versus the average size of the polycrystals as shown in Fig. 8. As clearly shown, the CO production rate and the average size of the polycrystals showed a good correlation. It is proposed that the larger polyhedral polycrystals loaded with Ag cocatalyst would be advantageous for the higher photocatalytic activity for the $\mathrm{CO}_{2}$ reduction. As shown in Fig. 4d, the $\mathrm{CTO}(\mathrm{NaCl}, 40)$ sample would have less defects than the $\mathrm{CTO}(\mathrm{NaCl}, 5)$ sample. These results suggest that the large polyhedral polycrystals with the flat facets and with fewer defects would be suitable for the photocatalytic reduction of $\mathrm{CO}_{2}$ with water to produce $\mathrm{CO}$. 
In order to elucidate the reason why the $\mathrm{CO}$ production rate decreased with time at the initial stage as shown in Fig. 5, the state of the Ag particles on the $\mathrm{Ag}(0.1) / \mathrm{CTO}(\mathrm{NaCl}, 50)$ sample before and after the reaction test were examined. This photocatalyst also exhibited the constant activity for producing $\mathrm{CO}$ and $\mathrm{H}_{2}$ after initial period for $5 \mathrm{~h}$ until $24 \mathrm{~h}$ later (not shown but similar to Fig. 5). In the DR UV-visible spectra (Fig. 9a), the sample before use exhibited a broad band with the maximum at $470 \mathrm{~nm}$ in wavelength assignable to the localized surface plasmon resonance (LSPR) of the Ag nanoparticles. After the use in the photocatalytic reaction, the band maximum shifted to shorter wavelength around $420 \mathrm{~nm}$ (Fig. 9b), suggesting the variation of the state of the Ag nanoparticle, i.e., the particle size of the Ag nanoparticle would become slightly smaller. Figure 10 shows the FE-SEM images recorded in a reflection mode, where the Ag particles could be observed as while dots (highlighted by the circles). On the $\operatorname{Ag}(0.1) / \mathrm{CTO}(\mathrm{NaCl}, 50)$ sample, various size of Ag nanoparticles were scattered before the reaction (Fig. 10a), while the particles were located on some specific large and flat facets after the reaction test for $24 \mathrm{~h}$ (Fig. 10b). Generally, it is considered that the photoformed holes and electrons can oxidize and reduce both deposited nanoparticles and adsorbed molecules and ions on the photocatalyst surface. In the present study, since the Ag nanoparticles were deposited by the photodeposition method under air atmosphere and Ag might be photoreduced before adsorbed by the photocatalyst surface, the Ag nanoparticles might be partially oxidized or deposited even on the oxidative sites. This means that the metallic Ag atom in the Ag nanoparticles on the oxidative sites can be oxidized to $\mathrm{Ag}^{+}$cation and released from the metallic particles while the released $\mathrm{Ag}^{+}$cation can be reduced to form metallic Ag nanoparticles on the reductive sites. If the facets on the polyhedral polycrystals could be divided into oxidative and reductive facets, Ag nanoparticles on the oxidative facets would disappear and Ag nanoparticles on the reductive facets would be stabilized to function as the reductive sites for $\mathrm{CO}_{2}$ reduction. On the $\mathrm{CTO}(\mathrm{NaCl}, 50)$ sample, several large polygonal facets on the polyhedral particles were observed in the SEM images (Fig. 10a and 10b). Before the reaction the Ag nanoparticles were dispersed on many facets. After the photocatalytic reaction, many Ag nanoparticles were found on some specific facets, where the Ag cocatalyst did not aggregate. This suggests that the Ag nanoparticles would be well stabilized on the large facets even after the photocatalytic reaction test. These facets would be the reductive facets. This dispersed and stabilized state of the Ag nanoparticles on the large and flat reductive facets would contribute to the constant and high photocatalytic activity in the steady state. 
On the other hand, the activity for the photocatalytic $\mathrm{CO}_{2}$ reduction of the $\mathrm{Ag}(0.1) / \mathrm{CTO}(\mathrm{SS}, 1273)$ sample gradually decreased for $20 \mathrm{~h}$ while the activity for water splitting maintained (Table 2, entry 11). The CTO(SS,1273) sample consisted of roundish particles connected together, where no large facets were observed (Fig. 10c and 10d). Although the Ag nanoparticles were dispersed on the surface before the reaction test (Fig. 10c), they aggregated so much after the reaction test probably due to the lack of the large flat facets (Fig. 10d). Thus, it is proposed that the aggregation of the Ag cocatalyst would be the reason for the decrease of the photocatalytic activity for $\mathrm{CO}_{2}$ reduction. These facts suggest that the $\mathrm{CO}_{2}$ reduction to $\mathrm{CO}$ would take place on the Ag cocatalyst surface and the water splitting to produce $\mathrm{H}_{2}$ would dominantly occur on the surface of the $\mathrm{CaTiO}_{3}$ photocatalyst. The high and stable photocatalytic activity of the $\mathrm{Ag} / \mathrm{CaTiO}_{3}$ photocatalysts prepared with $\mathrm{NaCl}$ flux for $\mathrm{CO}_{2}$ reduction would be achieved with the large flat facets stabilizing the Ag nanoparticles as the specific cocatalyst for $\mathrm{CO}$ formation. Although the positive effect of the large size of particles has been also reported and explained by the reduction of the recombination of the photoexcited electron and hole pairs, for example, for $\mathrm{WO}_{3}$ photocatalyst [39], the reason for the size effect in the present study would be different from the reported case.

\section{Conclusions}

Each flux, $\mathrm{CaCl}_{2}, \mathrm{KCl}$ and $\mathrm{NaCl}$, provided unique morphology of $\mathrm{CaTiO}_{3}$ particles in the flux method (the molten salt method). Among them, by using the $\mathrm{NaCl}$ flux with the moderate concentration of solute, the $\mathrm{CaTiO}_{3}$ samples consisting of the large polyhedral particles covered with large flat facets and with fewer defects could be prepared.

All the samples promoted the photocatalytic activity for $\mathrm{CO}_{2}$ reduction with water to produce $\mathrm{CO}$ and $\mathrm{O}_{2}$ and water splitting to produce $\mathrm{H}_{2}$ and $\mathrm{O}_{2}$, where the two reactions competitively proceeded. The polyhedral $\mathrm{CaTiO}_{3}$ photocatalyst with $\mathrm{Ag}$ cocatalyst exhibited a high and stable activity for the photocatalytic reduction of $\mathrm{CO}_{2}$, which was 10 times higher than the Ag-loaded $\mathrm{CaTiO}_{3}$ sample prepared by the solid state reaction method. It was revealed that the $\mathrm{CO}_{2}$ reduction for $\mathrm{CO}$ formation take place especially on the Ag cocatalyst, while the water splitting can proceed on the surface of $\mathrm{CaTiO}_{3}$ photocatalyst. The large flat facets on the polyhedral $\mathrm{CaTiO}_{3}$ particles of polycrystals would stabilize the Ag nanoparticles to promote the photocatalytic $\mathrm{CO}_{2}$ reduction to $\mathrm{CO}$. The most active photocatalyst prepared in the present study was the 
$\mathrm{Ag}(0.5) / \mathrm{CTO}(\mathrm{NaCl}, 40)$ sample, which exhibited the $\mathrm{CO}$ production rate of $0.35 \mu \mathrm{mol} \mathrm{h} \mathrm{h}^{-1}(0.2 \mathrm{~g}$ of the photocatalyst with the light of $0.35 \mathrm{~W}$ measured in the range of $254 \pm 10 \mathrm{~nm}$ ) and the selectivity for the $\mathrm{CO}_{2}$ reduction was $45 \%$ at the steady state.

\section{Acknowledgements}

We would like to thank Dr. Junya Ohyama for his help of XRD measurements. The SEM measurements were carried out by the help of Nano-fabrication platform at VBL, Nagoya University, under Nanotechnology platform, The Ministry of Education, Culture, Sports, Science and Technology (MEXT), Japan. This work was financially supported by Toyota Motor Corporation, a Grant-in-Aid for Scientific Research (B), (No. 25289285), a Grant-in-Aid for Scientific Research on Innovative Areas “All Nippon Artificial Photosynthesis Project for Living Earth (AnApple)” (No. 25107515) from the Japan Society for the Promotion of Science (JSPS), and the Program for Element Strategy Initiative for Catalysts \& Batteries (ESICB), commissioned by the MEXT of Japan.

\section{References}

[1] L. Yuliati, H. Yoshida, Chem. Soc. Rev. 37 (2008) 1592-1602.

[2] K. Shimura, H. Yoshida, Catal. Surv. Asia 18 (2014) 24-33.

[3] A. Kudo, Y. Miseki, Chem. Soc. Rev. 38 (2009) 253-278.

[4] Y. Inoue, Energy Environ. Sci. 2 (2009) 364-386.

[5] R. Abe, J. Photochem. Photobiol. C 11 (2010) 179-209.

[6] K. Maeda, K. Domen, J. Phys. Chem. Lett. 1 (2010) 2655-2661.

[7] J.C. Hemminger, R. Carr, G.A. Somorjai, Chem. Phys. Lett. 57 (1978) 100-104.

[8] M. Halmann, Nature 275 (1978) 115-116.

[9] T. Inoue, A. Fujishima, S. Konishi, K. Honda, Nature 277 (1979) 637-638.

[10] H. Yoshida, in "Energy efficiency and renewable energy through nanotechnology, Green energy and technology”, Ling Zang (Ed.), Springer-Verlag, London, 2011, Ch.15, 531-559.

[11] K. Sayama, H. Arakawa, J. Phys. Chem. 97 (1993) 531-533.

[12] K. Iizuka, T. Wato, Y. Miseki, K. Saito, A. Kudo. J. Am. Chem. Soc.133 (2011) 20863-20868. 
[13] Z. Like, E. Tanabe, K. Morikawa, T. Kazino, T. Sekihuzi, S. Matumoto, Y. Hirata and H. Yoshida, 108th Symposium of Catal. Soc., Kitami, Japan (2011) 1 D15.

[14] K. Teramura, Z. Wang, S. Hosokawa, Y. Sakata, T. Tanaka, Chem. Eur. J. 20 (2014) 9906-9909.

[15] N. Yamamoto, T. Yoshida, S. Yagi, Z. Like, T. Mizutani, S. Ogawa, H. Nameki, H. Yoshida, J. Surf. Sci. Nanotech. (2014), accepted.

[16] M. Yamamoto, T. Yoshida, N. Yamamoto, H. Yoshida, S. Yagi, J. Surf. Sci. Nanotech. (2014), accepted.

[17] J.S. Jang, P.H. Borse, J.S. Lee, K.T. Lim, O.S. Jung, E.D. Jeong, J.S. Bae, H.G. Kim, Bull. Korean Chem. Soc. 32 (2011) 95-99.

[18] H. Mizoguchi, K. Ueda, M. Orita, S.C. Moon, K. Kajihara, M. Hirano, H. Hosono, Mater. Res. Bull. 37 (2002) 2401-2406.

[19] K. Shimura, H. Yoshida, Energy Environ. Sci. 3 (2010) 615-617.

[20] K. Shimura, H. Miyanaga, H. Yoshida, Stud. Surf. Sci. Catal. 175 (2010) 85-92.

[21] J. Coreno, O. Coreno, J. Biomed. Mater. Res. A 75 (2005) 478-84.

[22] K. Teshima, K. Yubuta, S. Sugiura, T. Suzuki, T. Shishido, S. Oishi, Bull. Chem. Soc. Jpn. 79 (2006) 17251728.

[23] C.Y. Xu, J. Wu, P. Zhang, S.P. Hu, J.X. Cui, Z.Q. Wang, Y.D. Huang, L. Zhen, CrystEngComm 15 (2013) $3448-3454$.

[24] S. Suzuki, K. Teshima, M. Kiyohara, H. Kamikawa, K. Yubuta, T. Shishido, S. Oishi, CrystEngComm 14 (2012) 4176-4180.

[25] H. Yoshida, M. Takeuchi, M. Sato, L. Zhang, T. Teshima, M. G. Chaskar, Catal. Today 232 (2014) 158-164.

[26] H. Kato, M. Kobayashi, M. Hara, M. Kakihana, Catal. Sci. Technol. 3 (2013) 1733-1738.

[27] D. Arney, B. Porter, B. Greve, P.A. Maggard, J. Photochem. Photobiol. 199 (2008) 230-235.

[28] Q. Wang, T. Hisatomi, Y. Moriya, K. Maeda, K. Domen, Catal. Sci. Technol. 3 (2013) 2098-2103.

[29] D. Arney, T. Watkins, P. A. Maggardw, J. Am. Ceram. Soc. 94 (2011) 1483-1489.

[30] Y. Miseki, K. Saito, A. Kudo, Chem. Lett. 38 (2009) 180-181.

[31] Y. Hosogi, H. Kato, A. Kudo, J. Mater. Chem. 18 (2008) 647-653.

[32] J. Tauc, R. Grigorovici, A. Vancu, Phys. Status Solidi 15 (1966) 627-637.

[33] M. M. Elcombe, E. H. Kisi, K. D. Hawkins, T. J. White, P. Goodman, S. Matheson, Acta Cryst. B, 47 (1991) 305-314.

[34] J. Kiwi, M. Grätzel, J. Phys. Chem. 88 (1984) 1302-1307. 
[35] J. Kiwi, C. Morrison, J. Phys. Chem. 88 (1984) 6146-6152.

[36] K. Yamaguchi, S. Sato, J. Phys. Chem. 89 (1985) 5510-5513.

[37] G. Muneura, V. Rives-Arnau, A. Saucedo, J. Chem. Soc., Faraday Trans. 175 (1979)736-747.

[38] A. Gonzalez-Elipe, G. Muneura, J. Soria, J. Chem. Soc., Faraday Trans. 175 (1979) 748-761.

[39] F. Amano, E. Ishinaga, A. Yamanaka, J. Phys. Chem. C 117 (2013) 22584-22590. 
Table 1 Properties of the representative $\mathrm{CaTiO}_{3}$ samples

\begin{tabular}{llccc}
\hline \multirow{2}{*}{ Entry } & \multicolumn{1}{c}{ Sample } & Crystallite diameter ${ }^{a} / \mathrm{nm}$ & Bandgap $^{b} / \mathrm{eV}$ & BET specific surface area $^{c} / \mathrm{m}^{2} \mathrm{~g}^{-1}$ \\
\hline 1 & $\mathrm{CTO}\left(\mathrm{CaCl}_{2}, 5\right)$ & 99.6 & 3.54 & 19.1 \\
2 & $\mathrm{CTO}(\mathrm{KCl}, 5)$ & 25.3 & 3.64 & 3.62 \\
3 & $\mathrm{CTO}(\mathrm{NaCl}, 5)$ & 29.0 & 3.62 & 2.04 \\
4 & $\mathrm{CTO}(\mathrm{NaCl}, 40)$ & 26.7 & 3.60 & 1.10 \\
5 & $\mathrm{CTO}(\mathrm{SS}, 1273)$ & 26.2 & 3.60 & 1.67 \\
\hline
\end{tabular}

${ }^{a}$ Estimated from XRD. ${ }^{b}$ Estimated from DR UV-vis spectra. ${ }^{c}$ Estimated from $\mathrm{N}_{2}$ adsorption.

Table 2 Results of the reaction tests for the photocatalytic reduction of $\mathrm{CO}_{2}$ with $\mathrm{H}_{2} \mathrm{O}$ on the Ag/CTO samples.

\begin{tabular}{|c|c|c|c|c|c|c|c|c|c|c|c|}
\hline \multirow[t]{2}{*}{ Entry } & \multirow[t]{2}{*}{ Sample ${ }^{a}$} & \multicolumn{5}{|c|}{$\begin{array}{l}\text { Production rate (5 h later) } \\
/ \mu \mathrm{mol} \mathrm{h}^{-1}\end{array}$} & \multicolumn{5}{|c|}{$\begin{array}{l}\text { Production rate (20 h later) } \\
/ \mu \mathrm{mol} \mathrm{h}^{-1}\end{array}$} \\
\hline & & $\mathrm{CO}$ & $\mathrm{H}_{2}$ & $\mathrm{O}_{2}$ & $S_{C O}(\%)^{b}$ & $\mathrm{e}^{-} / \mathrm{h}^{+c}$ & $\mathrm{CO}$ & $\mathrm{H}_{2}$ & $\mathrm{O}_{2}$ & $S_{C O}(\%)^{b}$ & $\mathrm{e}^{-} / \mathrm{h}^{+c}$ \\
\hline 1 & $\mathrm{Ag}(0.1) / \mathrm{CTO}\left(\mathrm{CaCl}_{2}, 5\right)$ & 0.014 & 1.27 & 0.12 & 0.78 & 5.3 & 0.006 & 0.93 & 0.40 & 0.6 & 1.2 \\
\hline 2 & $\mathrm{Ag}(0.1) / \mathrm{CTO}(\mathrm{KCl}, 5)$ & 0.022 & 0.69 & 0.25 & 2.8 & 1.4 & 0.010 & 0.47 & 0.21 & 2.1 & 1.1 \\
\hline 3 & $\mathrm{Ag}(0.1) / \mathrm{CTO}(\mathrm{NaCl}, 5)$ & 0.080 & 0.40 & - & 17 & - & 0.036 & 0.36 & 0.16 & 9.1 & 1.2 \\
\hline 4 & Ag(0.1)/CTO(NaCl,50) & 0.24 & 0.60 & 0.53 & 29 & 0.80 & 0.24 & 0.67 & 0.52 & 26 & 0.87 \\
\hline 5 & Ag(0.1)/CTO(NaCl,90) & 0.083 & 0.57 & 0.13 & 13 & 2.5 & 0.060 & 0.40 & 0.26 & 13 & 0.90 \\
\hline 6 & Ag(0.5)/CTO(NaCl,20) & 0.17 & 0.32 & - & 34 & - & 0.093 & 0.19 & - & 33 & - \\
\hline 7 & $\operatorname{Ag}(0.5) / C T O(N a C l, 40)$ & 0.35 & 0.48 & 0.25 & 42 & 1.7 & 0.35 & 0.43 & 0.36 & 45 & 1.1 \\
\hline 8 & $\operatorname{Ag}(0.5) / C T O(N a C l, 50)$ & 0.45 & 0.56 & 0.35 & 44 & 1.5 & 0.29 & 0.53 & 0.39 & 35 & 1.1 \\
\hline 9 & Ag(0.5)/CTO(NaCl,60) & 0.20 & 0.46 & 0.21 & 29 & 1.5 & 0.21 & 0.40 & 0.28 & 35 & 1.1 \\
\hline 10 & $\operatorname{Ag}(0.5) / \mathrm{CTO}(\mathrm{NaCl}, 70)$ & 0.10 & 0.38 & 0.24 & 21 & 1.0 & 0.13 & 0.28 & 0.20 & 29 & 1.1 \\
\hline 11 & $\operatorname{Ag}(0.1) / C T O(S S, 1273)$ & 0.25 & 0.11 & - & 69 & - & 0.023 & 0.13 & - & 15 & - \\
\hline 12 & $\operatorname{Ag}(0.1) / \mathrm{CTO}(\mathrm{SS}, 1373)$ & 0.030 & 0.42 & - & 6.8 & - & 0.024 & 0.49 & - & 4.6 & - \\
\hline
\end{tabular}

${ }^{a}$ Loading amount of Ag cocatalyst was 0.1 or $0.5 \mathrm{wt} \%,{ }^{b}$ Selectivity to CO, see text, ${ }^{c}$ the ratio of the consumed electrons to the consumed holes, see text. 


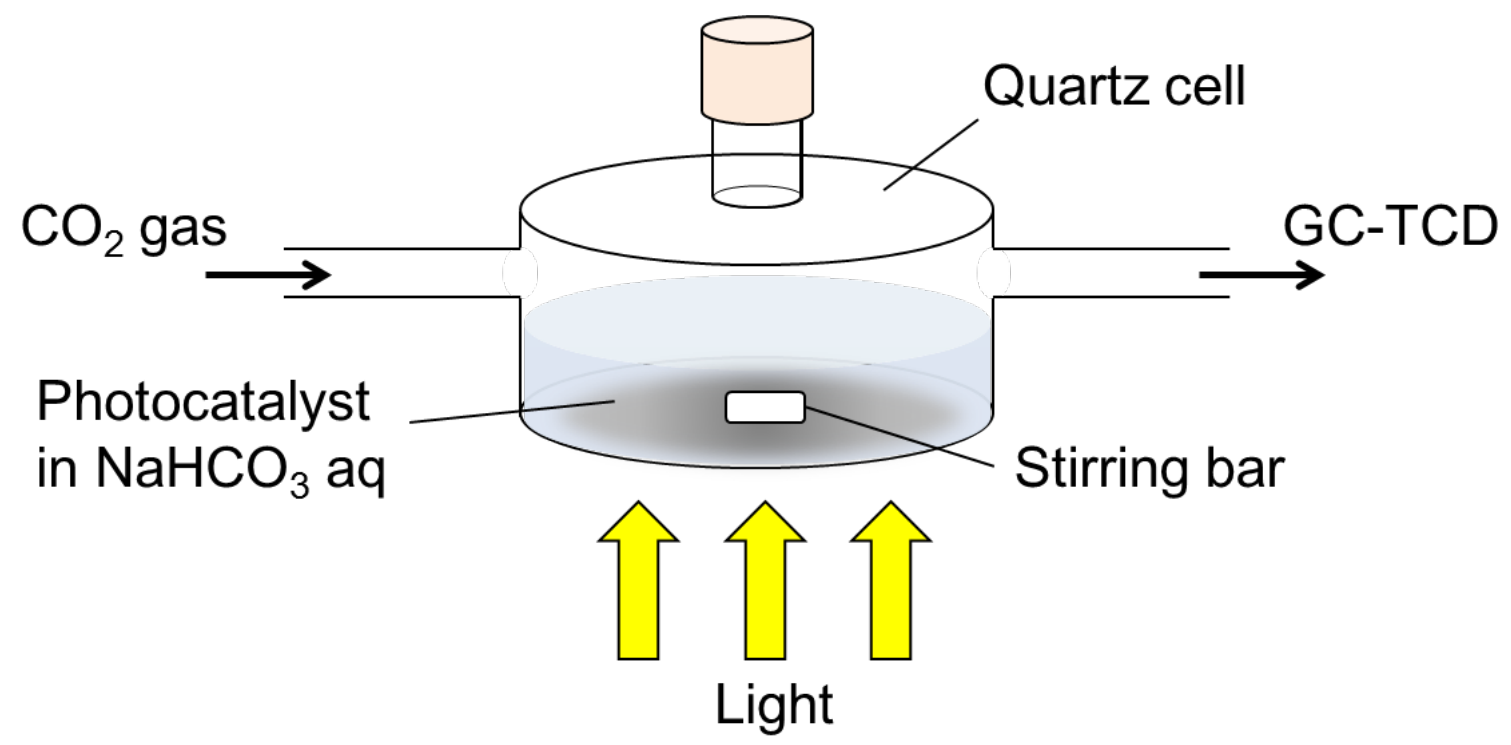

Fig. 1 Photocatalytic reactor for reduction of carbon dioxide with water. 


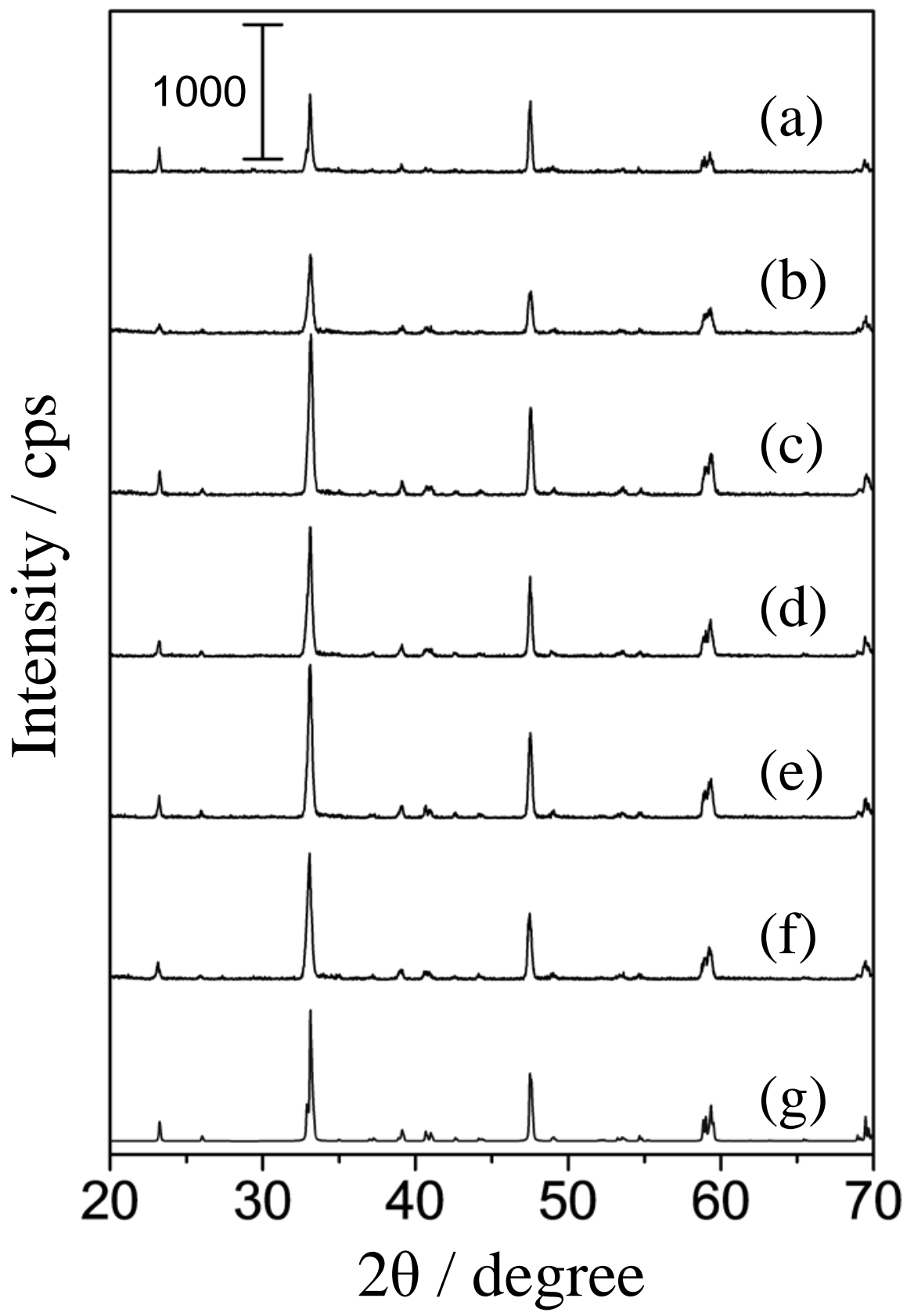

Fig. 2 XRD patterns of the $\mathrm{CTO}\left(\mathrm{CaCl}_{2}, 5\right)$ sample (a), the $\mathrm{CTO}(\mathrm{KCl}, 5)$ sample (b), the CTO $(\mathrm{NaCl}, 5)$ sample (c), the $\mathrm{CTO}(\mathrm{NaCl}, 40)$ sample (d), the $\mathrm{CTO}(\mathrm{NaCl}, 90)$ sample (e) and the CTO(SS,1273) sample (f), and a calculated one from a database ICSD \#74212 (g). 

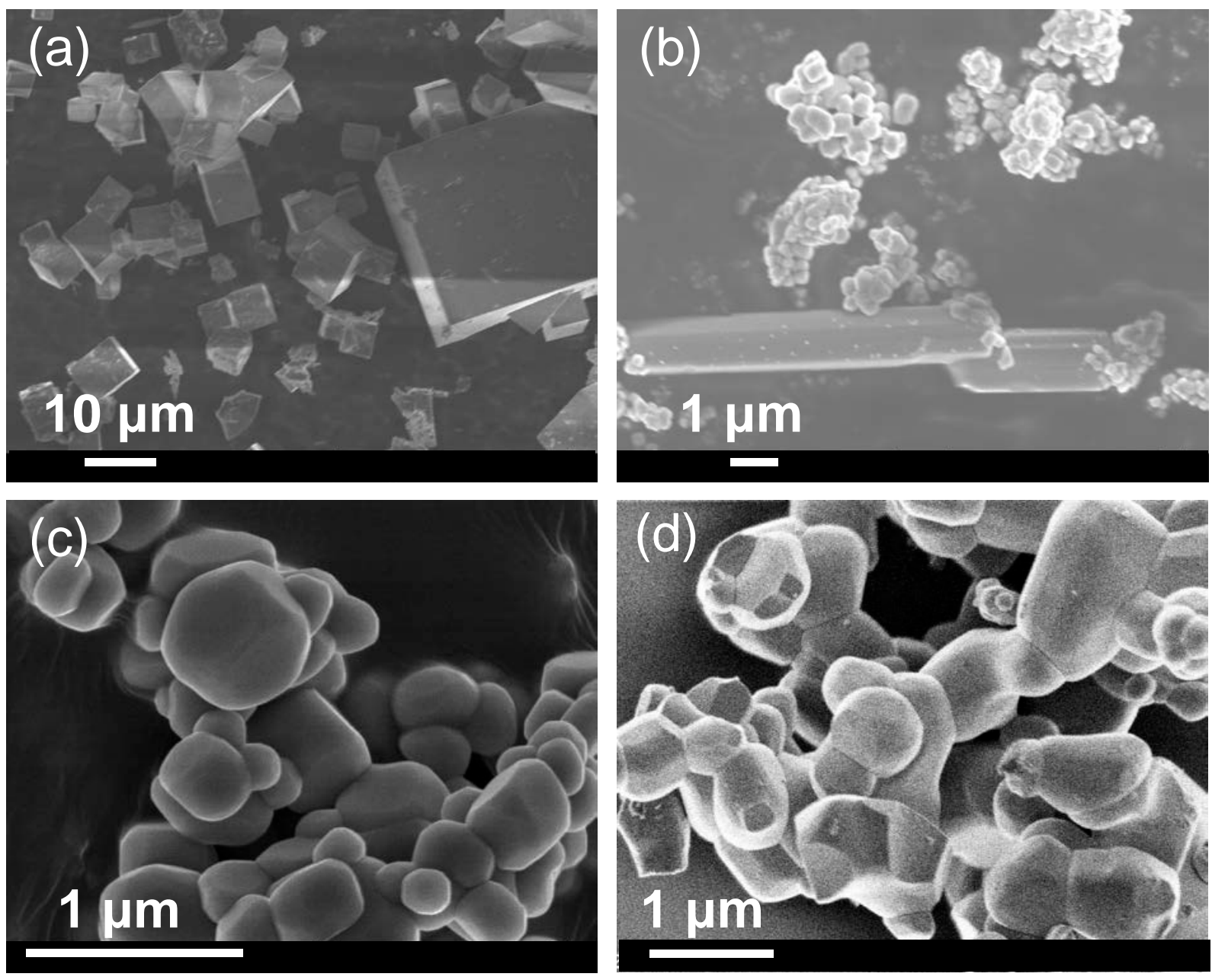

Fig. 3 FE-SEM images of the $\mathrm{CTO}\left(\mathrm{CaCl}_{2}, 5\right)$ sample (a), the $\mathrm{CTO}(\mathrm{KCl}, 5)$ sample (b), the CTO(NaCl,5) sample (c), and the CTO(SS,1273) sample (d). The images (a)-(c) were recorded by a JEOL JSM-7500FA and the image (d) was recorded by a Hitachi S-5200. 


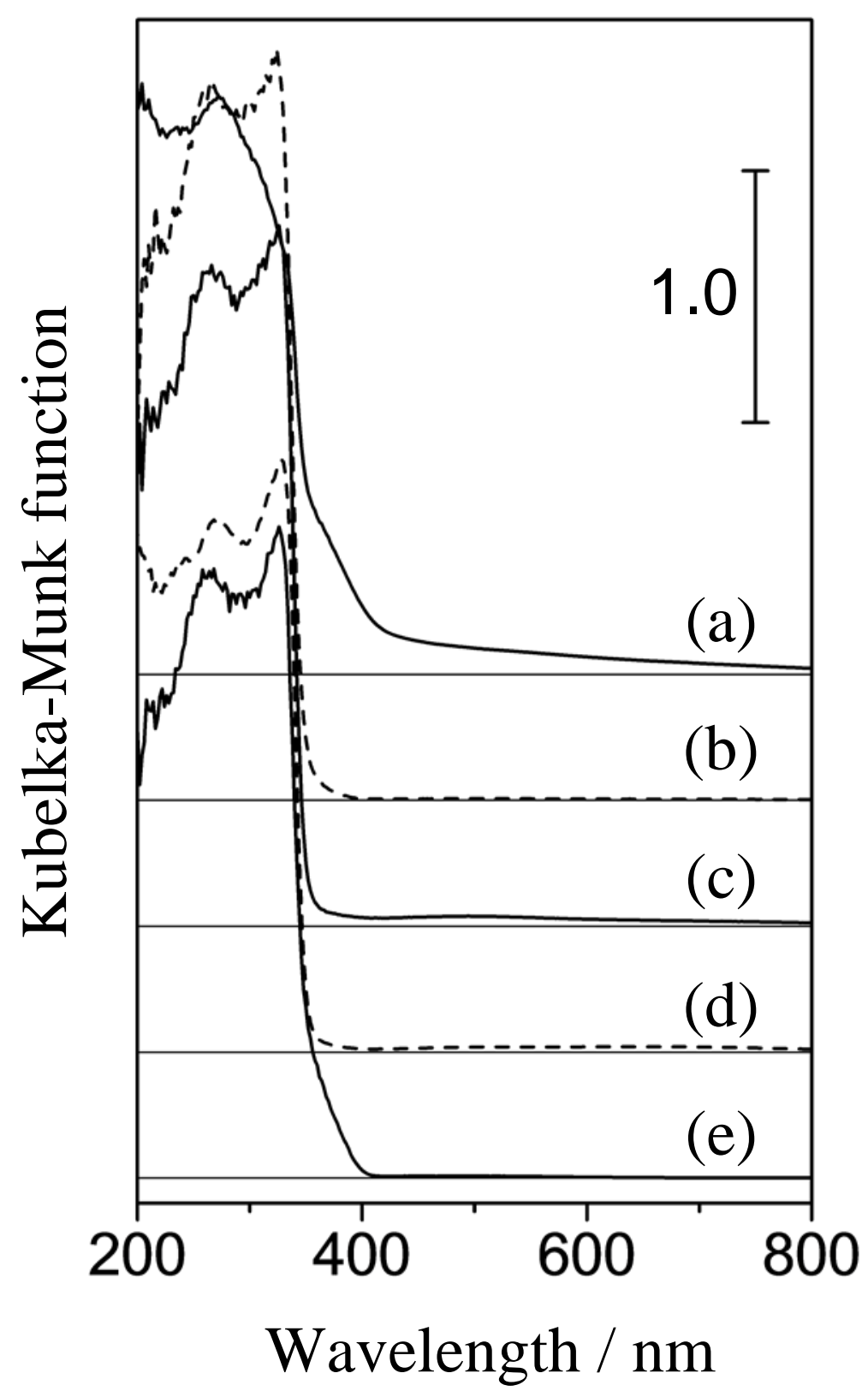

Fig. 4 DR UV-visible spectra of representative $\mathrm{CaTiO}_{3}$ samples; the $\mathrm{CTO}\left(\mathrm{CaCl}_{2}, 5\right)$ sample (a), the $\mathrm{CTO}(\mathrm{KCl}, 5)$ sample (b), the $\mathrm{CTO}(\mathrm{NaCl}, 5)$ sample $(\mathrm{c})$, the $\mathrm{CTO}(\mathrm{NaCl}, 40)$ sample $(\mathrm{d})$, and the CTO(SS,1273) sample (e). 


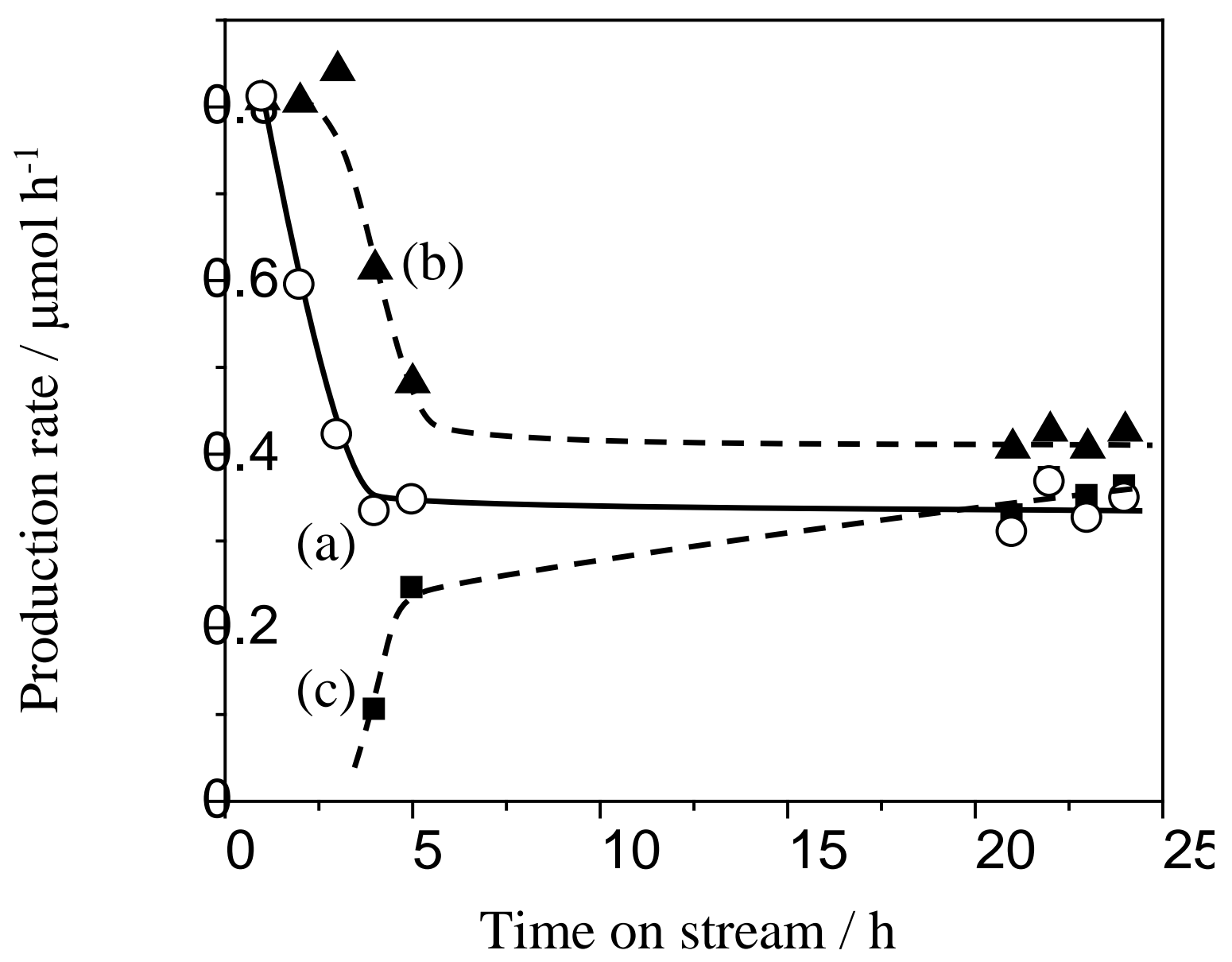

Fig. 5 Time course of the production rate of $\mathrm{CO}(\mathrm{a}), \mathrm{H}_{2}$ (b) and $\mathrm{O}_{2}$ (c) in the photocatalytic reduction of $\mathrm{CO}_{2}$ with water over the $\mathrm{Ag}(0.5) / \mathrm{CTO}(\mathrm{NaCl}, 40)$ sample. 

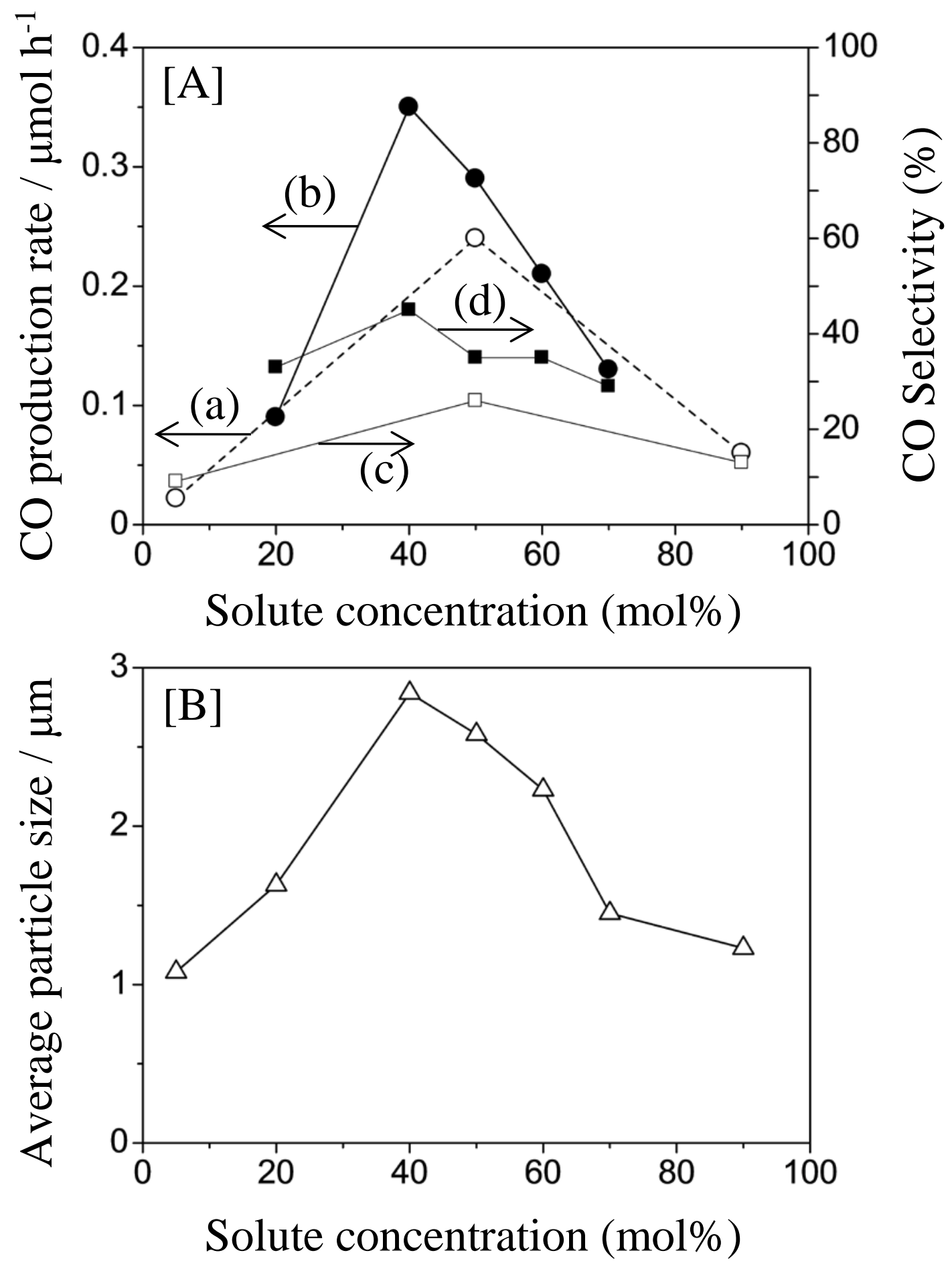

Fig. 6 [A] Variation of CO production rate (a,b) and $\mathrm{CO}$ selectivity (c,d) in the photocatalytic $\mathrm{CO}_{2}$ reduction with $\mathrm{H}_{2} \mathrm{O}$ on the $\mathrm{Ag}(0.1) / \mathrm{CTO}(\mathrm{NaCl}, x)$ samples $(\mathrm{a}, \mathrm{c})$ and those on the $\mathrm{Ag}(0.5) / \mathrm{CTO}(\mathrm{NaCl}, x)$ samples (b, d). [B] The average particle size of the CTO(NaCl, $x$ ) samples estimated by the SEM images versus the solute concentration during the preparation of the CTO(NaCl, $x$ ) samples by the flux method. 

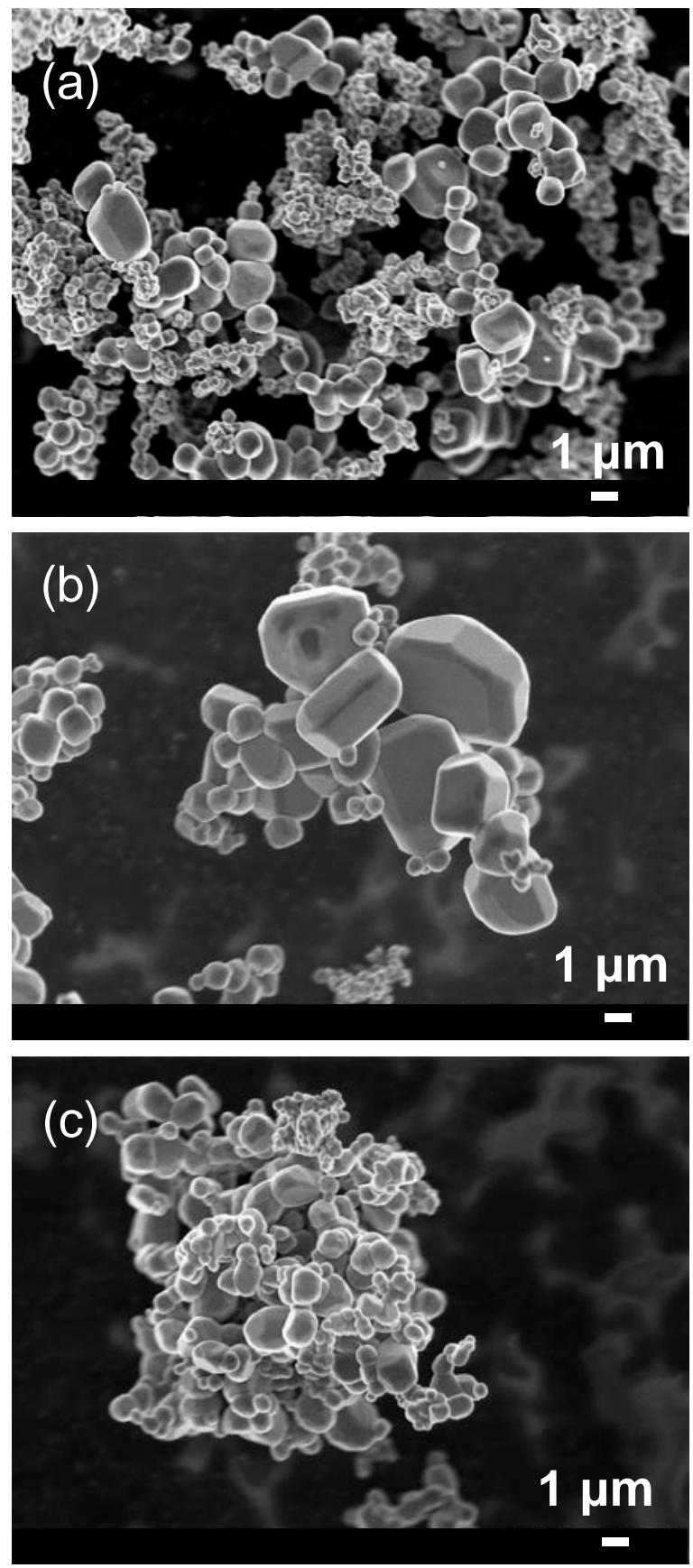

Fig. 7 FE-SEM images of the $\mathrm{CTO}(\mathrm{NaCl}, 20)$ sample (a) , the $\mathrm{CTO}(\mathrm{NaCl}, 40)$ sample (b) and the CTO(NaCl,70) sample (c), recorded by a Hitachi S-5200. 


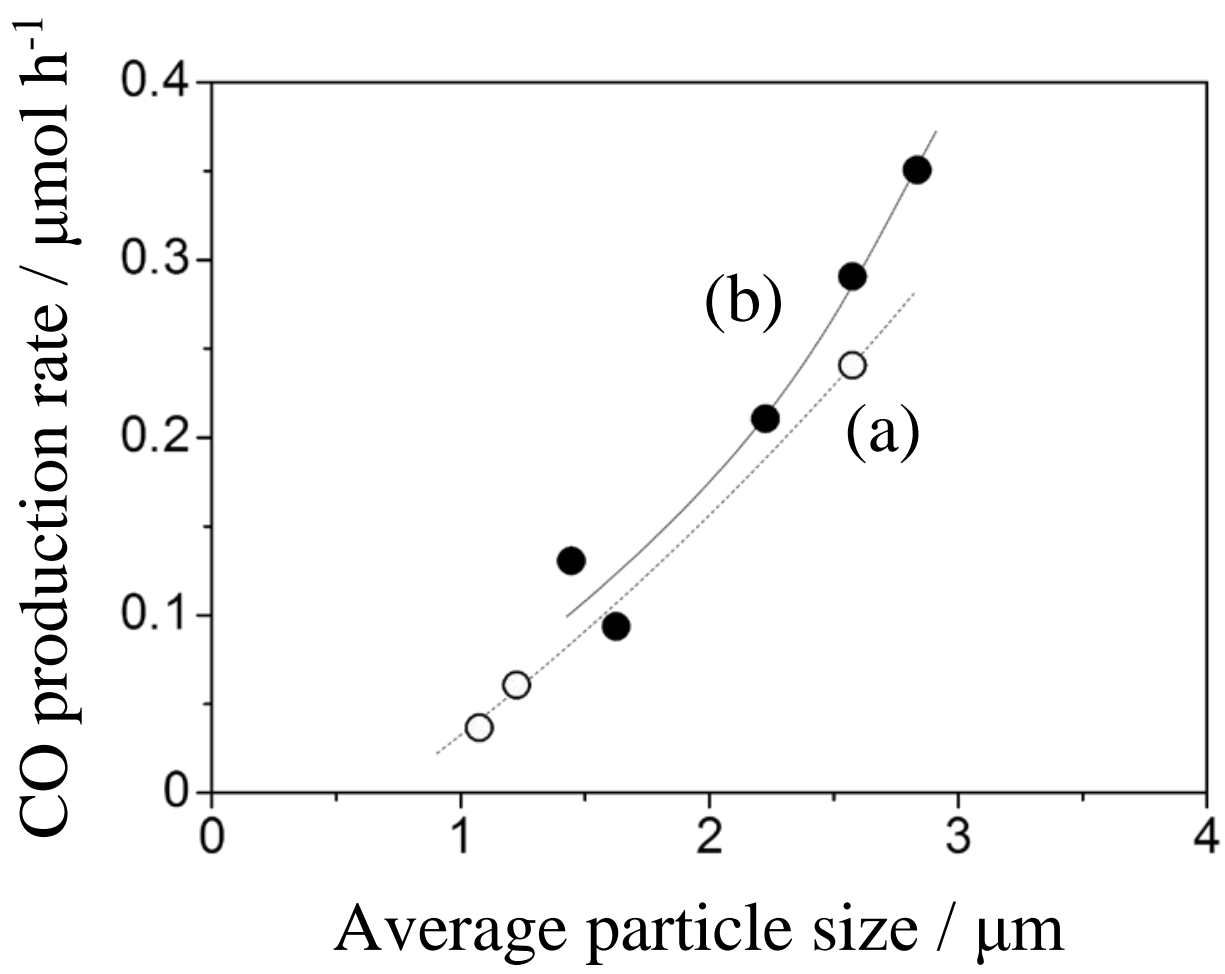

Fig. 8 Variation of the $\mathrm{CO}$ production rate on the $\mathrm{Ag}(0.1) / \mathrm{CTO}(\mathrm{NaCl}, x)$ samples (a) and the $\mathrm{Ag}(0.5) / \mathrm{CTO}(\mathrm{NaCl}, x)$ samples (b) versus the average particle size of the $\mathrm{CTO}(\mathrm{NaCl}, x)$ samples. 


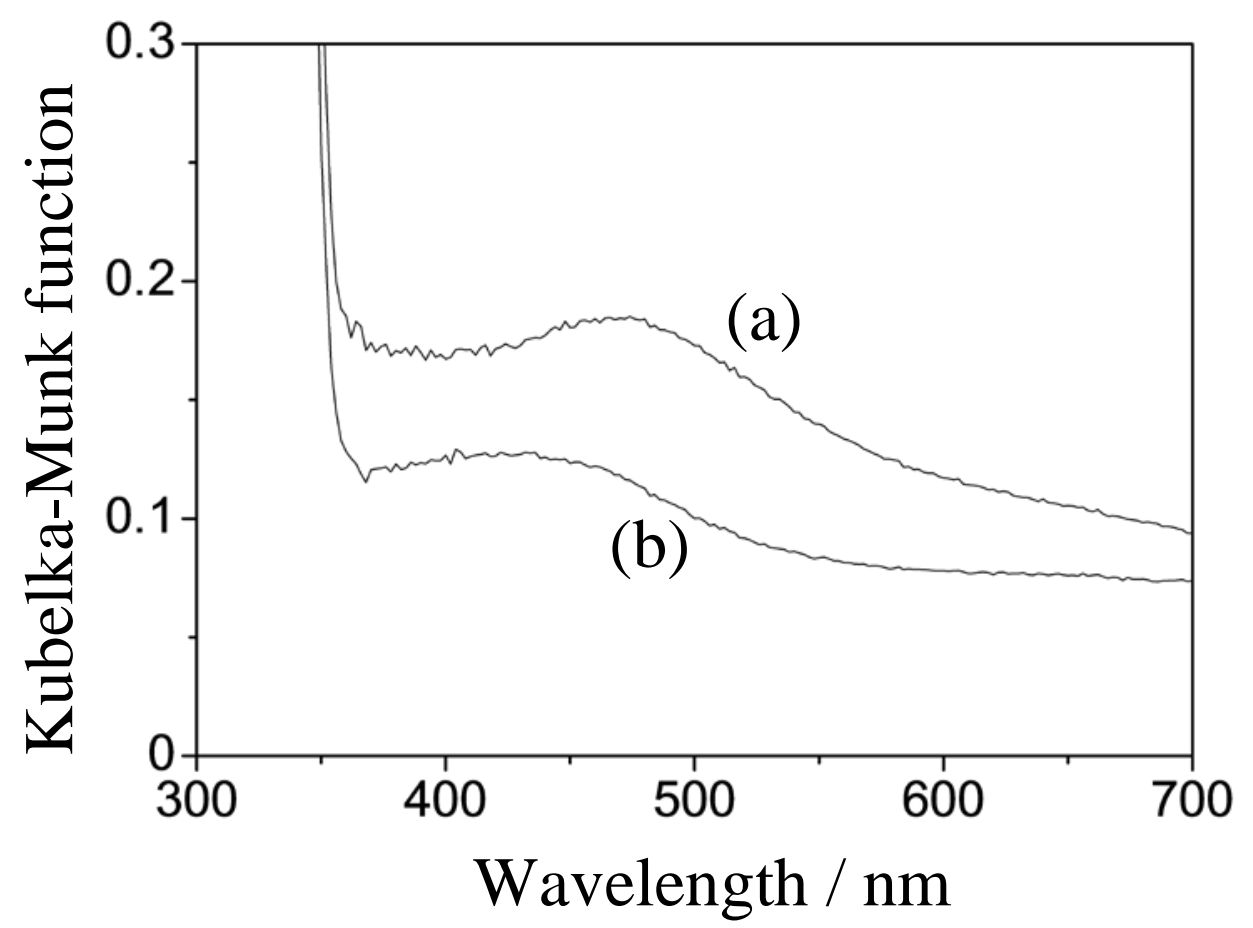

Fig. 9 DR UV-visible spectra of the $\mathrm{Ag}(0.1) / \mathrm{CTO}(\mathrm{NaCl}, 50)$ sample before (a) and after (b) use in the photocatalytic $\mathrm{CO}_{2}$ reduction with $\mathrm{H}_{2} \mathrm{O}$. 

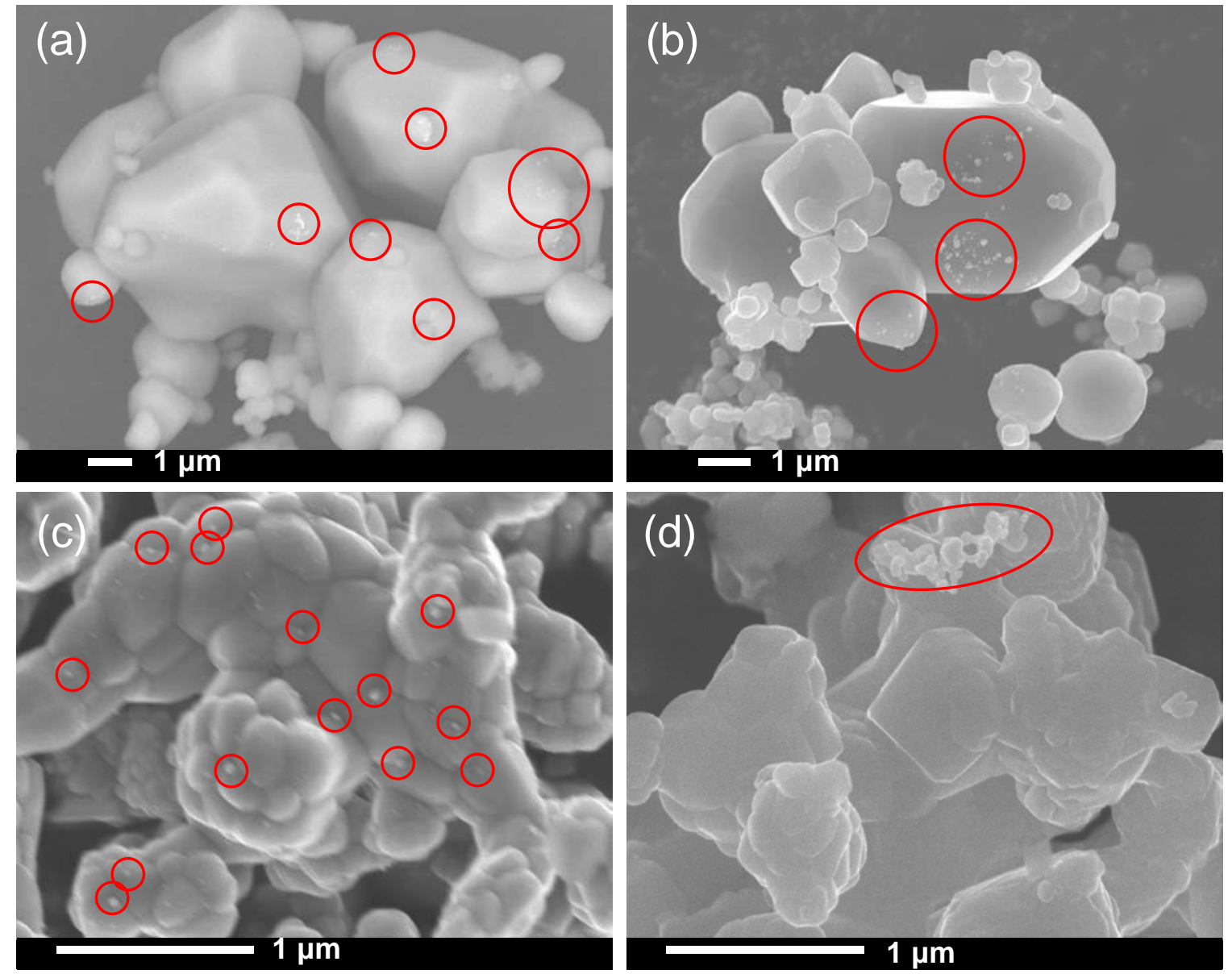

Fig. 10 FE-SEM images of the $\mathrm{Ag}(0.1) / \mathrm{CTO}(\mathrm{NaCl}, 50)$ sample before (a) and after (b) use and the $\mathrm{Ag}(0.1) / \mathrm{CTO}(\mathrm{SS}, 1273)$ sample before (c) and after (d) use in the photocatalytic $\mathrm{CO}_{2}$ reduction with $\mathrm{H}_{2} \mathrm{O}$. Circles highlight the Ag nanoparticles. 